\title{
Celebrating treatment completion in sub-Saharan Africa
}

Meaghann Shaw Weaver

I read with interest the Science \& Society article by Israëls et al. (Clinical trials to improve childhood cancer care and survival in sub-Saharan Africa. Nat. Rev. Clin. Oncol. 10, 599-604; 2013). ${ }^{1}$ This paper described the potential for paediatric oncology trials conducted in sub-Saharan Africa to advance the field's knowledge while extending health benefits to children regardless of their country's development index.
One of the major challenges in treating patients in low-resource settings is treatment completion. Despite much effort-which include patient-centred counselling, ${ }^{2}$ fee coverage, ${ }^{3}$ attentiveness to nutritional status, ${ }^{4}$ social support, ${ }^{5}$ infrastructure developments, ${ }^{6}$ gradual adaptation of treatment regimens with decreased toxicity, ${ }^{7,8}$ and collaborative partnerships 9 - the rates of treatment completion remain low, with reported abandonment rates of $40-50 \% .{ }^{10-13}$ I recently visited a twinning site in sub-Saharan Africa on the day of a patient's treatment completion. Treatment completion in this region is all too rare and seemingly cherished as a gift, quite timely as we enter the holiday season. Despite the lightheartedness of this poem, I join Israëls et al. ${ }^{1}$ in urging the serious and steadfast prioritization of improved childhood cancer care in sub-Saharan Africa.

\section{An ode to treatment completion in a low-income setting}

'Twas the patient's last day of chemo, when throughout the clinic,

All of us celebrated, turned believers from critics.

His infusion was hung by the bedside with care;

Here treatment completion is an event all too rare.

Other patients were nestled all snug in their beds, Where infectious disease funding has moved on ahead.

Noncommunicable diseases face funding caps,

Resulting too often in global oncology survival gaps.

Treatment barriers should make the world clatter, Toward urgent interventions to fix this stark matter. Disease progression and relapse occur in a flash, When system priorities and survival outcomes-clash.

Facing drug shortages, infrastructure limits, and access woes, Abandonment triumphs and cure rates are low. When, what to my wondering eyes should appear, This patient on protocol did persevere.

Through creative interventions, so lively and quick, With community togetherness his disease we did kick. More rapid than blasts his courses they came,

Recognizing barriers and calling out their shame.

"Now Vincristine! now, Etoposide! now, onward Cisplat! On, Methotrex!

On Leucovorin, and more supportive care for that!

To every child regardless of birth location,

Push for survival even in low-income nations!"
Aware that $50 \%{ }^{14}$ abandonment rate is too high,

To overcome obstacles-together we must ally.

We must ramp up completion interventions,

Give education, enablement, and empowerment attention.

Use behavioural targets such as reminder devices and incentives, Arm patients with information and communities with prevention. Form parent groups to address stigma and give patients support, Ensure food baskets, housing, and provision of transport.

In this era of genetic modalities and research translational, Remember this truth foundational: $80 \%{ }^{15}$ of children with cancer are facing despair, Now is the time for universal access to care.

High, middle, and low-income settings are in this together;

Collaboration will make survival curves better. In this holiday season of goodwill and charity, Partnership can narrow outcome disparity.

On this patient's last day of chemotherapy infusion, He reminds me a better world is not an illusion! He has successfully completed the treatment plan, Now he will grow into a healthy young man.

He is a living testimony to community support, His family's love and twinning teams to exhort. May this protocol be one of many completions we write,

For quality care to all children and cure as a health right.

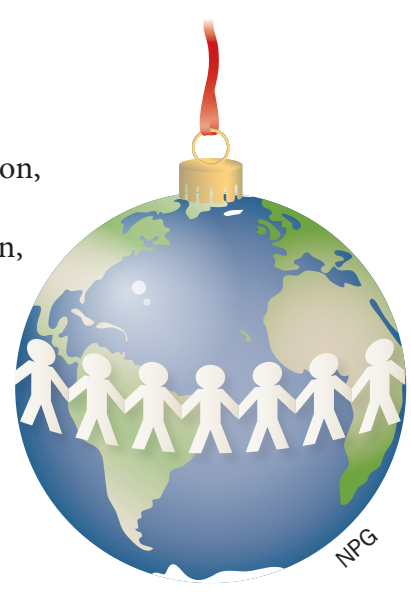




\section{CORRESPONDENCE}

Pediatric Oncology Fellow, St Jude Children's Research Hospital, 262 Danny Thomas Place, St Jude Children's Research Hospital, Memphis, TN 38105, USA.

meaghann.weaver@stjude.org

\section{Acknowledgements}

The author gives appreciation to the legacy of the St Jude International Outreach Program, particularly for the life work of Dr Raul Ribeiro. Thank you to Ms Mary Jean Kledzik for assistance in grammatical editing.

\section{Competing interests}

The author declares no competing interests.

1. Israëls, T. et al. Clinical trials to improve childhood cancer care and survival in subSaharan Africa. Nat. Rev. Clin. Oncol. 10, 599-604 (2013).

2. Ohaeri, B. M., Ofi, A. B. \& Campbell, O. B. Relationship of knowledge of psychosocial issues about cancer with psychic distress and adjustment among breast cancer clinic attendees in a Nigerian teaching hospital. Psycho-oncology 21, 419-426 (2012).
3. Scanlan, T. \& Kaijage, J. From Denis Burkitt to Dar es Salaam. What happened next in East Africa?-Tanzania's story. Br. J. Haematol. 156, 704-708 (2012).

4. Israëls, T. et al. Malnutrition and neutropenia in children treated for Burkitt lymphoma in Malawi. Pediatr. Blood Cancer 53, 47-52 (2009).

5. Israëls, T., Ribeiro, R. C. \& Molyneux, E. M. Strategies to improve care for children with cancer in Sub-Saharan Africa. Eur. J. Cancer 46 1960-1966 (2010)

6. Naresh, K. N. et al. Lymphomas in sub-Saharan Africa-what can we learn and how can we help in improving diagnosis, managing patients and fostering translational research? $\mathrm{Br}$. J. Haematol. 154, 696-703 (2011).

7. Harif, M. et al. Treatment of B-cell lymphoma with LMB modified protocols in Africa-report of the French-African Pediatric Oncology Group (GFAOP). Pediatr. Blood Cancer 50, 1138-1142 (2008).

8. Hesseling, P. B. et al. The Cameroon 2008 Burkitt lymphoma protocol: improved event-free survival with treatment adapted to disease stage and the response to induction therapy. Pediatr. Hematol. Oncol. 29, 119-129 (2012).
9. Kellie, S. J. \& Howard, S. C. Global child health priorities: what role for paediatric oncologists? Eur. J. Cancer 44, 2388-2396 (2008).

10. Arora, R. S., Eden, T. \& Pizer, B. The problem of treatment abandonment in children from developing countries with cancer. Pediatr. Blood Cancer 49, 941-946 (2007).

11. Yao, J. J. et al. Childhood cancer in Côte d'Ivoire, 1995-2004: challenges and hopes. S. Afr. Med. J. 103, 113-115 (2013).

12. Meremikwu, M. M. et al. Socioeconomic constraints to effective management of Burkitt's lymphoma in south-eastern Nigeria. Trop. Med. Int. Health 10, 92-98 (2005).

13. Hessissen, L. et al. Pediatric rhabdomyosarcoma in Morocco. Pediatr. Blood Cancer 54, 25-28 (2010).

14. Gupta, S. et al. The magnitude and predictors of abandonment of therapy in paediatric acute leukaemia in middle-income countries: a systematic review and meta-analysis. Eur. J. Cancer 49, 2555-2564 (2013).

15. Magrath, I. et al. Paediatric cancer in low-income and middle-income countries. Lancet Oncol. 14, e104-e116 (2013). 